See discussions, stats, and author profiles for this publication at: https://www.researchgate.net/publication/349078775

\title{
Theorizing inconsistent media selection in the digital environment
}

Preprint · February 2021

CITATIONS

0

3 authors:

(2) Marco Gui

Università degli Studi di Milano-Bicocca

37 PUBLICATIONS 428 CITATIONS

SEE PROFILE

(A) Mina Tsay-Vogel

Boston University

29 PUBLICATIONS 581 CITATIONS

SEE PROFILE

Some of the authors of this publication are also working on these related projects:

ICT \& learning outcomes View project

EU regional policy on education in Italy (2007-13) evaluation analysis View project
READS

18

James Shanahan

Indiana University Bloomington

92 PUBLICATIONS 5,322 CITATIONS

SEE PROFILE 
This is the pre-print version of the article accepted for publication in January 2021 in The

Information Society, published by Taylor \& Francis

\title{
Theorizing inconsistent media selection in the digital environment
}

\author{
Marco Gui ${ }^{\mathrm{a}}$ James Shanahan ${ }^{\mathrm{b}}$, and Mina Tsay-Vogel ${ }^{\mathrm{c}}$ \\ a Department of Sociology and Social Research, University of Milano-Bicocca, Milan, Italy; ${ }^{\mathrm{b}}$ The \\ Media School, Indiana University, Bloomington, Indiana, USA; 'Department of Mass \\ Communication, Advertising, and Public Relations, Boston University, Boston, Massachusetts, \\ USA.
}

\begin{abstract}
Choice inconsistency has long been studied in economics and psychology. In this article we critically review theories of media choice, showing that they have not explicitly dealt with this phenomenon. Although digitalization has recently made it more salient, the communication literature on inconsistent choice still remains highly fragmented. We draw on interdisciplinary literature to address blind spots in our theorization of inconsistent media selection.
\end{abstract}

\section{Introduction}

Understanding the determinants of exposure to media content and the processes through which choices are made among available options has long been a key objective of communication researchers and scholars from related disciplines. Research has extensively investigated the different kinds of gratifications people obtain from exposure to media (e.g. enjoyment, appreciation, satisfaction), focusing on the active role of users in choosing what content best meets their desires and urges. This is certainly the case with studies based on theories such as uses and gratifications (Blumler and Katz 1974; Conway and Rubin 1991), mood management (Zillmann 1988), selective exposure (Klapper 1960), and planned behavior (Hartmann 2009). In contrast to these theories of active selection, other theories explain media choice as the product of involuntary processes resulting from media consumption habits (LaRose 2010) or heuristics that are reinforced if they turn out to be ecologically convenient (Marewski, Galesic, and Gigerenzer 2009). More recently, a more subtle distinction has been proposed between "hedonic" and "eudaimonic" gratifications users obtain from media content (Oliver and Bartsch 2010). However, inconsistent media selection has attracted limited attention in media studies. Lately, digitalization has shifted scholars' attention to problematic media choices much more than before: concepts such as "media addiction" (LaRose, Lin, and Eastin 2003), "procrastination" (Meier, Reinecke, and Meltzer 2016; Reinecke et al. 2016), "self-regulation deficits" (LaRose 2009; LaRose, Lin, and Eastin 2003; Panek 2014), and "media multitasking" (Lang and Chrzan 2016; Levine, Waite, and Bowman 2012; Reinecke et al. 2017) have been proposed. However, there is a high degree of fragmentation in this literature and choice 
inconsistency is not dealt with directly. Moreover, much of this literature has presented problematic choices as an outcome of pathological mechanisms, in effect ruling out systematic "errors" in media choice by assumption. A more explicit theorization of choice inconsistency has been developed in behavioral economics and psychology literature, which has more and more considered it as a systematic and structural bias in human beings (Sen 1977; Thaler and Sunstein 2008; Tversky and Kahneman 1981).

In this article we review theories of media choice through the lens of behavioural economics literature on choice inconsistency. We first review how media choice theories have dealt with

problematic choices. We thereafter discuss how interdisciplinary research on inconsistent choice can help us address blind spots in our theorization of inconsistent media selection (IMS). Based on this research, we show that IMS is produced by specific conflicts between long-term and short-term preferences and it turns out to be a systematic and widespread behavior. We also show that IMS is potentially increasing in the digital environment, where the opportunities for instant gratification are multiplied. Finally, we propose a research agenda for future investigations into IMS.

\section{Rational choice, revealed preferences, and (in)consistent choices}

Traditional economic theory was based on the assumption that consumers manifest a "rational choice" in their behavior. This presumes that consumers are able to evaluate the benefits and costs of different purchase options, and also directly translate their desires into choices, considering available resources. Exploiting this approach in the realm of choice theory, Samuelson (1938) developed the concept of "revealed preferences," which posits that consumers' preferences are revealed by their consumption behavior, assuming perfect choice consistency. Methodologically, the revealed preferences approach is a way to infer the preferences of consumers given the observed choices.

In contrast, in the following decades, research on "bounded rationality" highlighted the limitations people experience when making a choice, related to time, cognition, and the decision situation (Gigerenzer and Selten 1983, 2001; Simon 1956, 1983). Later, Sen (1977) explicitly raised the problem of distinguishing between individual preferences, actual choices, and maximization of utility, three dimensions that were seen as overlapping in traditional rational choice theory. Other authors highlighted how actual choices reveal an "imperfect rationality" in human beings (Elster, 1977), which make people prone to a systematic weakness of will (or akrasia, as Aristotle called it) in consumption behavior (Winston, 1980). As Rieskamp, Busemeyer, and Mellers (2006) argue, preferences arise from a mixture of aspirations, thoughts, motives, emotions, beliefs, and desires and are not always clearly translatable into actual choices. Similarly, economic psychologists Amos Tversky and Daniel Kahneman, in a body of work that was recognized by a Nobel Prize for Kahneman, have shown that choices depend on how problems are formulated, posing another significant challenge for the theory of rational choice (e.g. Tversky and Kahneman 1981). Building on these insights, the recent empirical work on "nudge theory" (Thaler and Sunstein 2008) shows that choices can be nudged one way or another through a purposeful choice frame restructuring. These theoretical advances have explicitly debunked the idea that individuals are always capable of making the best choice in accordance with their utility maximization; they are prone to make inconsistent choices. In a review of the literature on choice inconsistency, Hsee and Hastie (2006) conclude that individuals often make suboptimal decisions due to two main reasons: they are not able to 
accurately predict the experiential consequence of their choice or - in the case where their predictions are correct - they are not able to make for various reasons choices that accord with their predictions. In this last case, choice inconsistency has been operationalized as the difference between choices made in different moments (time-inconsistency): either "contemplated from a removed, dispassionate perspective" or made under the urge of specific pleasure stimuli (Hoch \& Loewenstein, 1991, 492; Shiv \& Fedorikhin, 1999). In this theorization, inconsistency emerges from a conflict between different utility time-frames: one that maximizes immediate gratification and one that considers long-term utility. From this point of view, consumer satisfaction - seen as an indicator of consistency - is viewed as the ex-post evaluation made by the subject about a specific choice made or choice habit performed (Stanca et al., 2013). In other cases, consistency is measured through the effect of specific choices on subjective well-being (Gruber \& Mullainathan, 2005) or satisfaction for specific life-domains, as for example job-satisfaction (Frey, 2010).

Some economists have used such a theoretical approach in research on media consumption (Benesch et al. 2006; Stanca et al., 2013), showing evidence of frequent direct or indirect unsatisfaction of users for their selection choices. Theorizing on the basis of these evidences, IMS can be defined as selection of media content where priority is given to immediate gratification rather than to long-term preferences, so that when viewed ex-post the choice is evaluated negatively by the subject.

\section{How communication theories explain choice inconsistencies}

In this section, we critically review existing theories of media choice to evaluate if and how they have addressed inconsistent choice as described by behavioural economics. We also highlight the existing gaps in the explanation of IMS-related behaviors.

Traditional media choice research has usually addressed inconsistent media selection by rationalizing it. When empirical research found contradictions between television content choices and appreciation (Gunter and Wober 1992; Weimann, Brosius, and Wober 1992), researchers explained the inconsistencies as being caused by limited competitive offerings and other practical limitations (Gunter and Wober 1992), or by social desirability biases (Ang 1985). Following such a rational choice perspective, the uses and gratifications (U\&G) paradigm assumes that people consciously consume media to gratify a variety of psychological and social desires and needs (Blumler and Katz 1974). U\&G suggests that television and other media will be used more when they yield more gratifications. The idea that viewers are able to determine the goals of their media use, pursue them, and report them accurately has been challenged for being too optimistic and individualistic (Rosenstein and Grant 1997; Severin and Tankard 1997; Strizhakova and Krcmar 2003). To account for unexpected outcomes of media consumption, $\mathrm{U} \& \mathrm{G}$ has refined its approach and started identifying different types of audience activity depending on viewers' intention, distinguishing between selective media exposure and less active approaches (Levy and Windhal 1984). U\&G has also tried to explain problematic media use by distinguishing between "gratifications sought" and "gratifications obtained" (Palmgreen, Wenner, and Rayburn 1980): the potential mismatch between them may explain why inconsistency can emerge. Comparing traditional U\&G indicators with indicators of enjoyment for reality-based and fictional programming, Nabi et al. (2006) concluded that gratifications "perhaps when sought, they impart positive outcomes, but when unintentionally aroused in 
pursuit of other desires, they may interfere with enjoyment" (442). Here the implicit assumption of U\&G remains that media use must in some way be gratifying, otherwise it would be avoided. But then, people do engage in inconsistent media selection that leads to ex-post dissatisfaction in more than an occasional basis, which is at odds with the theory.

In a similar vein, mood management theory (MMT) focuses on media choice as a motivational process. According to MMT, the primary reason for media selection is the regulation of moods such that individuals strive to maintain or intensify positive mood states and terminate or reduce negative ones (Zillmann 1988; Zillmann and Bryant 1985). MMT, unlike U\&G theory, does not assume that individuals are consciously aware of the way affective states influence their media choices. However, MMT conceptualizes a number of mechanisms that underlie media selection (Bryant and Davies 2006). For instance, people in negative moods are more likely to gravitate toward hedonically appealing content as compared to those in positive moods based on a stronger desire to relieve their prevailing aversive state (Knobloch and Zillmann 2002).

Furthermore, excitatory homeostasis suggests that individuals use media stimuli to attain optimal levels of arousal (Bryant and Zillmann 1984). However, while MMT may explain why people immediately choose gratifying content to optimize arousal or distract themselves from negative mood states, it is unclear how MMT would help us understand why people choose media that results in poor mood regulation, particularly over the long-term.

It is possible that one's desire to heighten arousal is facilitated by sensation seeking motivations (Zuckerman 2014). Sensation seekers tend to search for experiences that are novel, thrilling, and intense and are more prone to take risks for the sake of these experiences (Zuckerman 2009). Perhaps MMT and U\&G should consider the extent to which sensation-seeking plays a role in the consumption of arousing content (e.g. dramatic and sensational content in the digital environment). Nevertheless, both theories do not fully address the habitual nature of inconsistent media choices, particularly in the case when ex-post satisfaction suffers. In line with more rationalistic perspectives of media choice, selective exposure theory suggests that people accept or reject messages based on content that aligns with their predispositions (Klapper 1960). In other words, individuals are more likely to turn to content that reinforces their existing perspectives, opinions, and ideas. Striving for consistency is a central tenet of the theory and has been well supported in a number of media-relevant domains ranging from entertainment to news (e.g. Bennett and Iyengar 2008; Taylor and Friedman 2014). It runs counter to the notion of choice inconsistency, and therefore selective exposure theory is unable to account for the selection of content for its immediate gratification which conflicts with satisfaction. According to the theory of planned behavior (TPB), "behavior that is at least to a certain degree under volitional control will be performed if people really want to perform it and if they have the resources and abilities to do so" (Hartmann 2009, 33). TPB is unable to fully explain inconsistent media behaviors, as it also takes a predominantly rational approach when applied to the consumption of media. Specifically, as inconsistent media choices go beyond conscious intentions, they also go beyond the purview of this theory. TPB has, however, been used to explain behaviors that are impulsive by suggesting an implementation intention, such that people can mindlessly engage in a behavior because they have a general intention to adopt it (Hartmann 2009). Some scholars argue that an implementation intention is behind any habit (Gollwitzer 1999). Nevertheless, what if, for example, the user does not manifest any intention to waste his or her time on junk news but he or she does it anyway? TPB is by definition incapable of explaining inconsistent behaviors, since from its standpoint "bad media habits appear to have turned beyond volitional control" (Hartmann 2009, 39). Alternatively, expectancy value theory 
(EVT) argues that behaviors are guided by people's perception of the probability and value of potential consequences (Fishbein and Ajzen 1975). In the context of soap opera viewing, however, Babrow (1989) found that one's expectancy-value judgements had only minimal effects on viewing intention - showing inconsistency between the actual media behavior and the rational judgement people make about the chosen content, which EVT does not factor in. Scholars have also employed the notion of subjective quality assessment to explain media selection. Specifically, Wolling (2009) argues that a user's decision to use media is based on the assessment of the features of the product by the user. The central assumption here is that "the more positive is the quality assessment in respect of the media product, the higher is the probability that this product will be selected and regularly used" (Wolling 2009, 87). Facing the challenge of mutually competitive demands or conflicting goals, this theoretical approach assumes that subjects choose media products that "best meet the mutually opposed demands in combination" (Wolling 2009, 93). But then, the theory assumes that such a combination yields the best possible option for the subject when IMS behaviors can also lead to suboptimal outcomes for the subjects.

Conversely, alternative theoretical approaches take a less rational and goal-oriented perspective. As an extension of social cognitive theory, LaRose and Eastin (2004) suggest that once media consumption is strongly habitualized, individuals no longer consciously evaluate each media choice's expected outcome because they rely on past positive outcomes. Sometimes, media exposure is only minimally the result of rational choice, or it is not the outcome of a choice at all. Rather, it results from involuntary automatic, mindless, or compulsive processes. Analyzing the concept of media habits, LaRose (2010) argues that habit, defined as a form of automaticity in media consumption, which develops as people repeat consumption behaviors in stable circumstances, co-determines media use along with conscious thought processes. Here problematic media consumption arises when one is in a dysphoric mood or when deficient selfregulation is present, e.g. when media consumption is a primary means of relieving dysphoria (LaRose, Lin, and Eastin 2003). For instance, Caplan (2010) found that the use of the Internet for mood regulation predicted deficient self-regulation of Internet use and consequently, negative outcomes. In effect, a habitual perspective on problematic media use suggests that it represents a "pathological condition." On the contrary, inconsistent choice selection in general is a systematic phenomenon which extends beyond the need to relieve dysphoria or the presence of deficient self-regulation in clinical terms (Hsee and Hastie 2006).

Other approaches that help to inform our understanding of media choices have considered the role of heuristics. Taking into account different message processing routes, the elaboration likelihood model (ELM) highlights the persuasive power of peripheral cues when people are in low elaboration or cognitive involvement states, and of strong message arguments in high elaboration conditions (Petty and Cacioppo 1986). In the context of digital media, where there is an overabundance of content choice, ELM may explain, for example, why sensational messages are particularly appealing for those in situations characterized as less involving (e.g. the content is considered irrelevant, motivation for and ability for processing is low). Researchers have also proposed the existence of specific heuristics that guide users' choices (e.g. recognition heuristics, fluency heuristics, take-the-best heuristics) and help them make good choices even if much of the information is not available (Gigerenzer and Todd 1999). Particularly interesting is the concept of ecological rationality, which suggests that a heuristic works well as long as it proves apt for the environment in which the choice is made (Marewski, Galesic, and Gigerenzer 2009). This approach seems fruitful in an overabundant environment, as many stimuli induce the use of 
heuristics. However, this process assumes a rational will to produce a good choice when a user tries to compare the appropriateness of alternatives, especially when he or she continuously evaluates the ecological rationality of heuristics. This condition is not always present in IMS. Interesting for its potential relevance for IMS is the "should vs. want" distinction, which has been proposed in general decision making (Milkman, Rogers, and Bazerman 2008) but also in media selection (Van Koningsbruggen, Hartmann, Eden, and Veling 2017). Eden, Johnson, and Hartmann (2017) examined experimentally selective exposure to films in an imagined selfcontrol scenario. Participants in the depletion condition were less likely to select films that were cognitively and affectively challenging (a "should" choice) and more likely to select fun, suspenseful, and ultimately less appreciated content ("want" choice). However, the should vs. want distinction only partially addresses IMS. Such a distinction has been used to differentiate specific types of content irrespective of their utility for the subject - a de-coupling potentially useful for studying IMS. But then, it does not help us understand issues related to suboptimal choice, e.g. case where "want choices" are those actually implemented and "should choices" are those which are considered by the subject as the best options that could have been chosen. Researchers in communication have also attempted to implicitly address inconsistent media use specifically in the domain of the digital environment. Recent work has analyzed the dysfunctional effects of task-switching during work sessions, showing that it is often driven by arousal and hedonic pleasure, as well as low cognitive control (David et al. 2015; van der Schuur, Baumgartner, Sumter, and Valkenburg 2015; Xu, Wang, and David 2016). Others have focused their efforts on the notion of media procrastination. Systematic procrastination has been detected in the use of digital media and is related to low trait self-control, habitual social media checking with a consequent negative impact on well-being (Breems and Basden 2014; Meier, Reinecke, and Meltzer 2016; Myrick 2015; Reinecke et al. 2016). Building on studies about desire conflicts in human behavior (see Hofmann, Baumeister, Förster, and Vohs 2012), Hofmann, Reinecke, Meier, and Oliver (2017) focused on self-control as a key variable to explain conflicts between digital users' daily life goals and their media desires. Selfdetermination theory (SDT) has also been used to explain problematic digital media consumption (Deci and Ryan 1985, 2000), which postulates the existence of three basic psychological needs: competence, autonomy, and relatedness. These needs that affect human behavior have also been linked to patterns in media consumption. For example, scholars have used this theory to argue that need satisfaction explains variability in media preferences and enjoyment (Ryan, Rigby, and Przybylski 2006). This same capacity of the media to satisfy basic psychological needs can lead to overconsumption as individuals who experience poor need satisfaction in other life domains can turn to media to fill this gap. In a review of these studies, Rigby and Ryan (2016) conclude that the less rich a person's real life is, the more he or she will be susceptible to seeking need satisfaction through the media and consequently to overuse media. Although such studies highlight a weakness of digital media users, they do not help us understand IMS as a systematic phenomenon because they focus on single factors. Also, similar to theories about mass media choice, these studies uniquely focus on psychological variables to explain IMS without considering that even people in a good socio-psychological state can suffer ex-post dissatisfaction from an inconsistent choice. Therefore, inconsistent choices in media consumption should be considered as not only a pathological behavior, but one that structurally affects media users. In sum, existing communication theories cannot adequately explain the phenomenon of IMS. 


\section{Blind spots and literature on inconsistent choices}

A number of blind spots would emerge if one tried to explain IMS with existing media theories. First, as in the pathologizing perspective, existing theories explain inconsistent media selection behaviors mostly by focusing on users' characteristics (e.g. motivations, plans, habits, selfcontrol). Implicitly, they tend to consider external choice conditions (e.g. alternative content, quantity of stimuli, interface design, social norms) as being less relevant to problematic users' choice.

Second, media choice theories have seldom considered the existence of different levels of preferences (e.g. long-term preferences vs. immediate gratification) in the same subject.

Although many contributions exist that distinguish between different kinds of gratifications, their coexistence and systematic conflict has seldom been considered explicitly. For example, a strand of literature differentiates between a hedonic and an eudaimonic dimension of media gratification (see Oliver 2008; Oliver and Bartsch 2010). However, this literature aims at explaining the good reasons why people expose themselves to content characterized by unpleasant immediate experiences that lead to eudaimonic gratifications (e.g. a moving drama). Such literature is not directed at explaining "wrong" choices derived from seeking hedonic gratifications instead of eudaimonic ones.

Third, media choice theories do not consider that users could be structurally weak in pursuing their long-term preferences and that inconsistent choice are made systematically in consumption behavior. In other words, media theories have not explicitly considered that people normally and habitually give in to media temptations which cause ex-post regret. As Hsee and Hastie (2006) clarify, in their research on subjective well-being and happiness, one common cause of inconsistency is the inability to make choices follow utility. In sum, so far media choice theories have not considered suboptimality in choice except in terms of pathological behavior. Therefore, to address these blind spots, we seek understandings from an interdisciplinary literature, especially on three factors that have been studied extensively by researchers of inconsistent choice in different disciplines and are also are particularly relevant for understanding inconsistent media choice in an era of digitization: the number of options, the easiness of task switching, and the physiological attractiveness of content. It is likely that other user-level factors, such as motivated cognition, spreading activation in the working memory network (Anderson 1983), and attention habits and - at the environmental level - immersiveness and interactivity, could have an impact on media choice inconsistency although its relationship with these factors has not been investigated so far.

\section{Number of options}

As the media market and technology have evolved, the number of mediated stimuli to which users are subjected daily has rapidly increased. In different social science disciplines there is empirical research showing that, paradoxically, a negative association exists between the range of available options and the ability of individuals to choose consistently. After reviewing decades of psychological studies on decision-making, Schwartz (2004) concluded that we would be better off if we embraced voluntary constraints on our freedom of choice. Little to no empirical work has been carried out in media choice research that examines Schwartz's paradox of choice. On the contrary, the number of choices is often invoked as premise for why selectivity will occur, when in fact it can lead to suboptimal choices.

One of the main reasons why a greater range of choices can be detrimental to satisfaction is that overabundance leaves individuals with fewer resources to evaluate the options, pushing them to 
rely more on quick and automatic decisions. The reflective-impulsive dual-process model indicates the existence of a "reflective" system, which is engaged when decisions based on knowledge are made, and an "impulsive" system, which works through associations and motivational orientations (Strack and Deutsch 2006). When resources such as cognitive capacity are depleted, impulsive processes are more likely to take over (Friese, Hofmann, and Wänke 2008). In a review of psychological studies, Baumeister et al. (2008) showed that subjects who had received a previous treatment that intensively exploited their control resources had poorer self-control. In turn, when self-control resources are depleted, subjects tend to make suboptimal choices more frequently and are more likely to be swayed by desires and cravings, decisions they may regret in the long run (Heshmat 2015; Reed, Reed, Chok, and Brozyna 2011), even if conventional wisdom would suggest the opposite. Other dual-process theories also assume that human behavior is a result of two distinct processes: an implicit (automatic) unconscious process and an explicit (controlled) conscious process. Kahneman (2003) referred to them as "intuition" and "reasoning." Fazio and Towles-Schwen (1999) advance a similar understanding of impulsive and controlled behavior and of the conflicts between them with their MODE ("motivation and opportunity as determinants" of the attitude-behavior relationship) model. They suggest that choices are influenced by controlled processes only if a person has sufficient motivation to engage in analytic reasoning and also resources (time and cognitive capacity) to do so. The MODE model has been employed specifically for the interpretation of media messages. Ewoldsen, Rhodes, and Fazio (2015) suggest that while pro-social media messages can foster deliberative reasoning, they tend to be less useful when the targeted behaviors are driven by spontaneous processes. This happens especially when the monetary cost of each option is low. For example, while the potentially dangerous outcomes associated with smoking would motivate people to carefully think before starting such a habit, research suggests that smoking initiation is typically much more spontaneous in nature.

Consistent with these empirical findings, studies have found that having access to more television channels in fact lowers users' satisfaction, even though according to rational choice theory a wider selection of television channels should increase consumers' utility (Benesch, Frey, and Stutzer 2006; Weimann 1996).

In fact, the growth in the number of media content options became an issue much before the Internet (Heeter 1985), although in the communication literature it has never been addressed as a factor associated with inconsistent media selection. Today, having to choose from among a plethora of options is a permanent condition for digital media users, bringing salience to the number of options as a factor in media choice. A few studies (Panek 2012; Stephens et al. 2017) have looked at how option overabundance influences digital media users' choices. For instance, in an experiment with American college students, Panek (2012) found that those who chose from a greater number of websites selected options that were independently rated (and that the subjects reported) as more immediately gratifying. On the hand, when students selected from a smaller set of options, they chose less immediately gratifying content.

\section{Task switching}

Empirical research shows that workflow interruptions are negatively related to job performance (Bailey and Konstan 2006) and job satisfaction (Baethge and Rigotti 2013; Kirkcaldy and Martin 2000) and positively related to feelings of irritation (Grebner et al. 2003). Moreover, task and mindset switching have been repeatedly found to deplete self-regulatory resources (Hamilton, 
Vohs, Sellier, and Meyvis 2011; Rubinstein, Meyer, and Evans 2001). In media consumption, switching from one source to another has become easier and more common through the decades. In television, the increase in the number of channels and, most of all, the spread of the remote control in the 1970s, encouraged more "active" viewing, where viewers decided what they wanted to watch in real-time. However, this newer condition of easy switching between channels resulted in more "unplanned" exposure reflecting a lack of involvement with the program (Nathanson, Perse, and Ferguson 1997). Other technologies associated with more linear consumption styles, such as the VCR and DVR, were found to enhance viewers' satisfaction and enjoyment (Ferguson and Perse 2004; Perse and Ferguson 1993).

In the digital media environment, task-switching is much easier and more frequent, and also prompted by notifications and other push technologies (Yeykelis, Cummings, and Reeves 2014). Indeed, task switching (commonly referred to as "multitasking") is a structural affordance of digital media in that multiple windows can be kept open simultaneously and different devices can be used jointly. Scholars in the cognitive sciences suggest that task switching is largely responsible for users' sharp drop in cognitive performance, due to the depletion of cognitive resources (Lepp, Barkley, and Karpinski 2014; Ophir, Nass, and Wagner 2009). Kazakova, Cauberghe, Pandelaere, and De Pelsmacker (2015) showed that media multitasking behavior substantially alters the way users process media content. In particular, the fragmented nature of media multitasking leads to a narrower attentional focus and more concrete (low-level) construals that carry over to subsequent tasks, lowering users' capability of conceptually making sense of the situation. The literature is starting to highlight a relationship between digital technology features, such as their multitasking capacity and their ubiquitous portability, and users' tendency toward distractibility and impulsivity (Levine, Waite, and Bowman 2012, 2013).

\section{Physiological attraction}

Numerous studies have addressed the attention-attraction power of specific kinds of content. In general, sensational, and extraordinary events tend to be overrepresented in the media (Altheide 2004; McQuail 2010). The probability of something to be reported in news has been shown to be related to features such as deviance (Shoemaker, Danielian, and Brendlinger 1991), novelty and titillation (Meyers 1996), voyeurism (Baruh 2009), predictability, simplification, individualism, sex, violence and other such factors (Jewkes 2004). Experimental psychologists have sought to explain how individuals' attention is attracted and maintained through physiological arousal, regardless of their explicit decisions. For example, attention-catching mechanisms have been analyzed in empirical studies on formal characteristics of the media systematically responsible for eliciting physiological arousal in viewers (Grabe, Zhou, and Barnett 2001; Lang, Shin, Bradley, and Wang 2005). For measuring selective attention, methods include EOS (Eyes on Screen; see Miller 2006), heart rate (Lang, Potter, and Grabe 2003), secondary task reaction time (Basil 1994), and tracking of alpha frequency of the electroencephalogram (Simons, Detenber, Cuthbert, Schwartz, and Reiss 2003). Television content analysis has already shown that media producers exploit these mechanisms to retain viewers' attention in a competitive environment. Accordingly, messages have become shorter and faster (Bellamy and Walker 1996), and more shorthand visual techniques have been employed (Eastman and Neal-Lunsford 1993). As far as content is concerned, arousing features mostly coincide with those traditionally used in studies on newsworthiness. Uribe and Gunter (2007) identified several content categories that can be linked to emotional arousal such as sex, violence, destruction, humor, and celebrity. Schupp et al. (2004) showed that attention is particularly heightened when subjects are exposed to content that 
strongly activates appetitive and defensive motivational systems (i.e., when attention is drawn to all signs of threat and harm).

Over-consumption of content that elicits automatic attraction has been shown to negatively impact users' satisfaction. Weaver and Wilson (2009) found that the insertion of television violence within a program diminished reported enjoyment, even though violence is commonly positively related to audience ratings. A meta-analysis by Weaver (2011) based on 65 studies about the effects of violence on selective exposure and enjoyment confirmed that violent content increases exposure but decreases enjoyment in viewers. These findings were also confirmed experimentally (Weaver and Kobach 2012). In another experimental study, Stanca, Gui, and Gallucci (2013) found that when verbal violence is present in talk-shows, subjects watch more of a given program while reporting a significantly lower satisfaction level for the overall viewing experience. Attraction and satisfaction therefore appear to potentially diverge in the presence of sensational content.

In the context of digital media, physiologically attractive content is even more abundant because competition for users' attention is stronger: revenues are generated from clicks within a pay-perclick model (Kapoor, Dwivedi, and Piercy 2016) and companies make use of big data, such as web analytics, to monitor in real time the attractiveness of content (Chen, Conroy, and Rubin 2015; Tandoc 2014). Therefore, catchy headlines and enticing pictures, commonly referred to as "clickbait" are often used on the web. Such content often makes use of forward-referring techniques to induce anticipation and curiosity (Blom and Hansen 2015). Employing eyetracking measures, Pengate (2016) found that clickbait headlines evoked users' arousal, subsequently increasing their intention to read news stories. These conditions make the attractiveness of content more directly manipulated and exploited. Moreover, the attraction power of streaming video interacts with self-control such that when it becomes a proximate option, those low in self-control will more likely opt for immediate gratification rather than delayed benefit, followed by expressing feelings of guilt (Panek 2014).

Physiologically and formally "attractive" content represents a challenge for users' ability to delay gratification, an ability that has been found to strongly correlate with cognitive and academic performance and skills to cope with frustration and stress (Shoda, Mischel, and Peake 1990), as well as interpersonal relationship management (Tangney, Baumeister, and Boone 2004). However, attraction and satisfaction don't have to diverge all the time in the presence of sensational content: immediate gratification can also be gratifying when it does not overcome long-term preferences.

\section{Rethinking inconsistent media selection}

\section{${ }^{1}$ Notes}

In order to automatically detect clickbait headlines, Chakraborty, Paranjape, Kakarla, and Ganguly (2016) analyzed the characteristics of clickbait and non-clickbait content. Their findings indicate that clickbait headlines were longer and had shorter words, longer syntactic dependencies, higher presence of cardinal numbers, more unusual punctuation patterns, more hyperbolic words, and greater use of first and second person (i.e., I, we, you) voices. 
Clearly, as the preceding discussion shows, we need to examine inconsistent media selection in a systematic way. In the light of behavioural economic theory on choice inconsistency (Hoch \& Loewenstein 1991; Heshmat 2015), we consider the different time-frames of preferences: shortterm preferences with a maximization of immediate pleasure and long-term postponing enjoyments as a result of reasoned action. We can start by looking at the various ways in which these different kinds of preferences override each other and lead to outcomes in terms of satisfaction:

(1) long-term preferences override short-term preferences and actual choice leads to ex-post satisfaction; we consider this a consistent choice.

(2) long-term override short-term preferences and actual choice leads to ex-post dissatisfaction; this is an inconsistent but rare choice, not examined in this article.

(3) short-term override long-term preferences and actual choice leads to ex-post satisfaction; this is a consistent choice.

(4) short-term override long-term preference and actual choice leads to ex-post dissatisfaction, this is the more common type of inconsistency that we have prioritized in this article.

To elucidate, the first type of media selection is not problematic, as it leads to ex-post satisfaction. The second type is rare and has not drawn the attention of researchers of inconsistent choice in other fields. This can happen, for example, when a person is too strict with herself and leaves no room for beneficial relaxation. However, the focus of this article is on the much more common and studied case (4) when a subject opts for immediate gratification favored by the structure of the media environment and attractive content - conflicting with longterm preferences and causing dissatisfaction. The third type can be found in situations such as "serendipity," when - for example - someone is browsing randomly on the Internet but casually encounters something very useful for her long-term goals (see Beale 2007). Incidental exposure to news which enriches viewers' knowledge, even though they did not have an explicit intention to search for that specific information (Tewksbury, Weaver, and Maddex 2001; Prior 2007; Lee and Kim 2017), would be another example. However, such instances lack systematicity - one is unlikely to repeat the experience next time; it is difficult to "seek" serendipity or incidental exposure to news. The fourth type (immediate-gratification IMS) is of particular importance for communication scholars for three reasons. One, as we have seen, it occurs often. Two, it is an obstacle for improving people's quality of life. Three, it can be addressed through education and other types of intervention.

Existing communication research does not adequately address immediate-gratification IMS. As we showed in previous sections, both theories of media choice and more recent work on problematic digital media consumption have neglected a number of factors. In particular, these theories do not consider how the environment can push towards immediate-gratification IMS irrespective of users' psychological characteristics; they do not factor in the existence of 
different and conflicting levels of preferences $^{2}$ and, most of all, they do not consider the possibility of systematic suboptimal choices in media users' behavior.

Drawing from an interdisciplinary literature, we have shown that the number of options available, the ease of task switching, and the physiological attractiveness of content positively impact the likelihood of choice inconsistency in media consumption. In particular, people who choose under conditions of cognitive depletion due to an overabundance of options, with an easy access to alternative options and under physiological or emotional stimulation, often regret their choice afterwards. Digital media take these conditions to unprecedented heights, so making choice inconsistency a more salient issue in media consumption.

In the light of this review, immediate gratification-IMS emerges as a systematic (not a pathological) behavior in media consumption that can be more or less stimulated and strengthened depending on a number of factors. Further, predictors of immediate gratificationIMS are identifiable across three different domains: users' characteristics, environmental characteristics, and content characteristics. In particular, immediate gratification-IMS can be experienced more frequently in the following conditions:

1) At the user level, when there is low self-control/deficient self-regulation, high mood-regulation needs, high sensation-seeking, poor need satisfaction;

2) At the environmental level, when there is a large number of options and greater ease of content and task switching both between devices and within them;

3) At the content level, when content is physiologically attractive (e.g. violent, sexualized, sensational), messages are short and fast, and clickbait-like text is used to headline them.

While media choice theories have so far illuminated in depth the first condition, they have lagged behind other disciplines regarding the second and third conditions. A more careful consideration of the downsides of content overabundance and task switching are in particular needed to understand the influences of environmental factors on immediate gratification-IMS. As we have seen, interdisciplinary literature can help us understand how these conditions shape human choice behavior. Finally, the physiological attractiveness of content, both in its formal and substantive features, has to be considered as a facilitating factor for immediate gratification-IMS. Since these factors facilitate unsatisfactory outcomes and are present in a more extreme way in the digital environment, research on immediate gratificationIMS should be considered central to the study of well-being of digital users.

Regarding methodological issues, how can scholars measure and analyze immediate gratification-IMS? First, as short-term preferences for immediately gratifying content and a lack of ex-post satisfaction are the main indicators of immediate gratification-IMS, scholars should be able to measure the co-occurrence of these two phenomena. For the first, a number of methods are available, e.g. measures of physiological activation, content analysis, self-reports. For the second, self-reports are traditional means for investigating ex-post satisfaction, as in the tradition of the literature on subjective well-being (Frey and Stutzer 1999). However, measuring satisfaction in such a way can be particularly misleading (Grenadier and Wang 2007), when users are under the sway of an attractive stimulus. In general, a combination of media use

${ }^{2}$ In the literature on choice inconsistency, ex-post satisfaction is defined as "experienced utility" (utility as hedonic experience) rather than "decision utility" (utility as a representation of preference) (Kahneman and Sugden 2005). 
observation in combination with ex-post satisfaction measures would be the appropriate methodological mix to investigate immediate gratification-IMS.

If the framework that has been proposed here were appropriate, we should expect that specific occurrences of immediate gratification-IMS would be explained by a combination of three conditions identified above. Future studies on immediate gratification-IMS should analyze specific combinations of factors associated with these conditions. Future research will be able to better explain why, how, and in what conditions people are more prone to immediate gratification-IMS. Specifically, it is possible that physiological attraction for content intensifies as the number of options increases. For example, a clickbait link on a social media platform should be clicked more when the user is already cognitively depleted by many hours spent online. To take a different example, self-control deficits should offer fewer chances to drive users to immediate gratification-IMS in an environment where multitasking is minimized. In addition, future research should develop and test effective strategies to manage the negative consequences of immediate gratification-IMS. Moreover, the presence of social differences in the ability to confront challenges pertaining to immediate gratification-IMS should also be investigated. Indeed, similar to the well-established findings that heavy viewers of television were more likely to belong to underprivileged segments of the population, especially among youth (see for example Krosnick, Anand, and Hartl 2003), we already have some clues that immediate gratification-IMS in the digital world occurs more frequently and disruptively among those with low education or income (Gui and Büchi 2019). If this is the case, as far as immediate gratification-IMS can have negative consequences on different kinds of life outcomes, the theoretical framework proposed here can also guide educational and policy interventions. How can policies be developed to help people make more effective media choices, particularly in environments characterized by overabundant and sensational stimuli? What are the skills necessary to face this more demanding environment in terms of control resources? Such interventions could be informed by understanding of factors associated with the three conditions. It is possible that pre-commitment strategies (see Elster 2000) are successful at the user level, specific device settings could be optimal at the environment level, and the avoidance of particular content types could be best at the content level.

Policies that affect media interfaces could help reduce inconsistent choices and increase satisfaction among media users. In particular, one may consider interfaces that prevent excessive multitasking or automatic recommendations to users when their navigation behavior shows signs of immediate gratification-IMS, such as software that monitors time and behavior to reduce digital overuse (e.g. RescueTime, Toggl). This is in line with what "nudging" policies suggest (see Thaler and Sunstein 2008): to exploit alternative ways to present choices that positively impact consumers' behavior. Also, media literacy interventions could help people, especially the younger generation, to be familiarized with users' tendency to choose inconsistently online and the necessary skills and tools to minimize it. Our theoretical proposal can also offer hardware and software companies a better understanding of the different factors affecting inconsistent choice online in order to help them develop a more effective design to prevent it.

\section{References}

Altheide, D. L. 2004. Media logic and political communication. Political Communication 21(3): 293-296. 
Anderson, J. R. 1983. A spreading activation theory of memory. Journal of Verbal Learning and Verbal Behavior 22(3): 261-295.

Ang, I. 1985. Watching Dallas: Soap opera and the melodramatic imagination. New York: Methuen.

Babrow, A. S. 1989. An expectancy-value analysis of the student soap opera audience. Communication Research 16(2): 155-178. doi: 10.1177/009365089016002001

Baethge, A., and T. Rigotti. 2013. Interruptions to workflow: Their relationship with irritation and satisfaction with performance, and the mediating roles of time pressure and mental demands. Work \& Stress 27(1): 43-63.

Bailey, B. P., and J. A. Konstan. 2006. On the need for attention-aware systems: Measuring effects of interruption on task performance, error rate, and affective state. Computers in Human Behavior 22(4): 685-708.

Baruh, L. 2009. Publicized intimacies on reality television: An analysis of voyeuristic content and its contribution to the appeal of reality programming. Journal of Broadcasting \& Electronic Media 53(2): 190-210. http://dx.doi.org/10.1080/08838150902907678

Basil, M. D. 1994. Secondary reaction-time measures. In Measuring psychological responses to media, ed. A. Lang, 85-98. Hillsdale, NJ: Lawrence Erlbaum and Associates.

Baumeister R. F., Sparks, E. A., Stillman, T. F., and K. D. Vohs. 2008. Free will in consumer behavior: Self-control, ego depletion and choice. Journal of Consumer Psychology, 18(1): 4-13.

Beale, R. 2007. Supporting serendipity: Using ambient intelligence to augment user exploration for data mining and web browsing. International Journal of Human-Computer Studies 65(5): 421-433.

Bellamy, R.V. and J. R. Walker. 1996. Television and the remote control: Grazing on a vast wasteland. New York: Guilford press.

Benesch, C., Frey, B. S., and A. Stutzer. 2006. TV channels, self-control and happiness (Working Paper No. 301). Zurich: Institute for Empirical Research in Economics, University of Zurich.

Bennett, W. L., and S. Iyengar. 2008. A new era of minimal effects? The changing foundations of political communication. Journal of Communication 58(4): 707-731.

Blom, J. N., and K. R. Hansen. 2015. Click bait: Forward-reference as lure in online news headlines. Journal of Pragmatics 76: 87-100.

Blumler, J. and E. Katz. 1974. The uses of mass communication. Thousand Oaks, CA: Sage.

Breems, N., and A. Basden. 2014. Understanding of computers and procrastination: A philosophical approach. Computers in Human Behavior 31: 211-223.

Bryant, J., and J. Davies. 2006. Selective exposure to video games. In Playing video games: Motives, responses, and consequences, eds. P. Vorderer and J. Bryant, 181-194. Mahwah, NJ: Erlbaum.

Bryant, J., and D. Zillmann. 1984. Using television to alleviate boredom and stress: Selective exposure as a function of induced excitational states. Journal of Broadcasting 28(1): $1-20$.

Caplan, S. E. 2010. Theory and measurement of generalized problematic Internet use: A twostep approach. Computers in Human Behavior 26(5): 1089-1097.

Chakraborty, A., Paranjape, B., Kakarla, S., and N. Ganguly. 2016. Stop clickbait: Detecting and preventing clickbaits in online news media. In Advances in social networks analysis and mining, 9-16. New York: IEEE. 
Chen, Y., Conroy, N. J., \& Rubin, V. L. (2015). Misleading Online Content: Recognizing Clickbait as? False News?. In Proceedings of the 2015 ACM on Workshop on Multimodal Deception Detection (pp. 15-19). ACM.

Conway, J. C., and A. M. Rubin. 1991. Psychological predictors of television viewing motivation. Communication Research 18(4): 443-463.

David, P., Kim, J. H., Brickman, J. S., Ran, W., \& Curtis, C. M. (2015). Mobile phone distraction while studying. New Media \& Society, 17(10), 1661-1679.

Deci, E. L., \& Ryan, R. M. (1985). Intrinsic motivation and self-determination in human behavior. New York: Plenum.

Deci, E. L., \& Ryan, R. M. (2000). The "what" and "why" of goal pursuits: Human needs and the self-determination of behavior. Psychological Inquiry, 11, 227-268.

Eastman, S.T. \& Neal-Lunsford, J. (1993). The RCD's impact on programming and production. In Walker J. J. R. \& Bellamy R. (Eds.), The remote control device in the new age of television (pp. 189-210). New York: Praeger.

Eden, A., Johnson, B. K., \& Hartmann, T. (2017). Entertainment as a Creature Comfort: SelfControl and Selection of Challenging Media. Media Psychology, 1-25.

Elster, J. (1977). Ulysses and the sirens: A theory of imperfect rationality. Information (International Social Science Council), 16(5), 469-526.

Elster, J. 2000. Ulysses unbound: Studies in rationality, precommitment, and constraints. Cambridge, UK: Cambridge University Press.

Ewoldsen, D. R., Rhodes, N., \& Fazio, R. H. (2015). The MODE model and its implications for studying the media. Media Psychology, 18(3), 312-337.

Fazio, R. H., \& Towles-Schwen, T. (1999). The MODE model of attitude-behavior processes. Dual-process theories in social psychology, 97-116.

Ferguson, D. A., \& Perse, E. M. (2004). Audience satisfaction among TiVo and ReplayTV users. Journal of Interactive Advertising, 4(2), 1-8.

Fishbein, M., \& Ajzen, I. (1975). Belief, attitude, intention, and behavior. Reading, MA: Addison-Wesley.

Frey, B. S. (2010). Happiness: A revolution in economics. MIT press.

Frey, B.S. and Stutzer, A. (1999). Measuring Preferences by Subjective Well-Being. Journal of Institutional and Theoretical Economics, 155, 755-788.

Friese, M., Hofmann, W., \& Wänke, M. (2008). When impulses take over: Moderated predictive validity of explicit and implicit attitude measures in predicting food choice and consumption behaviour. British Journal of Social Psychology, 47(3), 397-419.

Gigerenzer, G., \& Selten, R. (2001). Rethinking rationality. In Gigerenzer, G., \& Reinhard S. eds. (2001). Bounded Rationality: The Adaptive Toolbox. Cambridge: MIT Press.

Gigerenzer, G., \& Todd, P. M. (1999). Fast and frugal heuristics: The adaptive toolbox. In Simple heuristics that make us smart (pp. 3-34). New York: Oxford University Press.

Gollwitzer, P. M. (1999). Implementation intentions: strong effects of simple plans. American Psychologist, 54(7), 493.

Grabe, M. E., Zhou, S., \& Barnett, B. (2001). Explicating sensationalism in television news: Content and the bells and whistles of form. Journal of Broadcasting \& Electronic Media, 45(4), 635-655.

Grebner, S., Semmer, N., Faso, L. L., Gut, S., Kälin, W., \& Elfering, A. (2003). Working conditions, well-being, and job-related attitudes among call centre agents. European Journal of Work and Organizational Psychology, 12(4), 341-365. 
Grenadier, S. R., \& Wang, N. (2007). Investment under uncertainty and time-inconsistent preferences. Journal of Financial Economics, 84(1), 2-39.).

Gui, M., and M. Büchi. 2019. From use to overuse: Digital inequality in the age of communication abundance. Social Science Computer Review, Online first. doi: $10.1177 / 0894439319851163$

Gunter, B., \& Wober, M. (1992). The reactive viewer. London: John Libbey and Company.

Hamilton, R., Vohs, K. D., Sellier, A. L., \& Meyvis, T. (2011). Being of two minds: Switching mindsets exhausts self-regulatory resources. Organizational Behavior and Human Decision Processes, 115(1), 13-24.

Hartmann, T. 2009. Action theory, theory of planned behavior and media choice. In Media choice: A theoretical and empirical overview, ed. T. Hartmann, 32-52. New York: Routledge.

Heeter, C. (1985). Program selection with abundance of choice. Human Communication Research, 12(1), 126-152.

Heshmat S. 2015. Addiction: A behavioral economic perspective. New York: Routledge

Hofmann, W., Baumeister, R. F., Förster, G., \& Vohs, K. D. (2012). Everyday temptations: an experience sampling study of desire, conflict, and self-control. Journal of Personality and Social Psychology, 102(6), 1318.

Hofmann, W., Reinecke, L., Meier, A., \& Oliver, M. B. (2017). Of sweet temptations and bitter aftertaste: self-control as a moderator of the effects of media use on well-being. The Routledge handbook of media use and well-being: international perspectives on theory and research on positive media effects. New York: Routledge, 211-222.

Hsee C. K., \& Hastie, R. (2006). Decision and experience: Why don't we choose what makes us happy? Trends in Cognitive Sciences, 10 (1), 31-37.

Jewkes, Y. (2004). The construction of crime news. Media and Crime, 35-62.

Kahneman, D., and R. Sugden. 2005. Experienced utility as a standard of policy evaluation.

Environmental and Resource Economics 32(1): 161-181.

Kahneman, D. (2003). Maps of bounded rationality: Psychology for behavioral economics. The American Economic Review, 93(5), 1449-1475.

Kapoor, K. K., Dwivedi, Y. K., \& Piercy, N. C. (2016). Pay-per-click advertising: A literature review. The Marketing Review, 16(2), 183-202.

Kazakova, S., Cauberghe, V., Pandelaere, M., \& De Pelsmacker, P. (2015). Can't see the forest for the trees? The effect of media multitasking on cognitive processing style. Media Psychology, 18(4), 425-450.

Kirkcaldy, B. D., \& Martin, T. (2000). Job stress and satisfaction among nurses: individual differences. Stress and health, 16(2), 77-89.

Klapper, J. T. (1960). The effects of mass communication. Glencoe: Free Press.

Knobloch, S., \& Zillmann, D. (2002). Appeal of love themes in popular music. Psychological Reports, 93, 653-658. doi: 10.2466/pr0.2003.93.3.653

Krosnick, J. A., Anand, S. N., \& Hartl, S. P. (2003). Psychosocial predictors of heavy television viewing among preadolescents and adolescents. Basic and Applied social psychology, 25(2), 87-110.

Lang, A., and J. Chrzan. 2016. Media multitasking: Good, bad, or ugly? Annals of the International Communication Association, 39(1), 99-128. 
Lang A., Potter D., and M. E. Grabe. 2003. Making news memorable: Applying theory to the production of local television news. Journal of Broadcasting \& Electronic Media 47(1): 113-123.

Lang A., Shin, M., Bradley, S., \& Wang, Z. (2005). Wait! Don't turn that dial! More excitement to come! The effects of story length and production pacing in local television news on channel changing behavior and information processing in a free choice environment. Journal of Broadcasting \& Electronic Media, 49(1), 3-22.

LaRose, R., \& Eastin, M. S. (2004). A social cognitive theory of Internet uses and gratifications: Toward a new model of media attendance. Journal of Broadcasting \& Electronic Media, 48(3), 358-377.

LaRose, R., Lin, C. A., \& Eastin, M. S. (2003). Unregulated Internet usage: Addiction, habit, or deficient self-regulation? Media Psychology, 5(3), 225-253.

LaRose, R. (2009). Social cognitive theories of media selection. Media choice: A theoretical and empirical overview, 10-31.

LaRose, R. (2010). The problem of media habits. Communication Theory, 20(2), 194-222.

Lee, J. K., \& Kim, E. (2017). Incidental exposure to news: Predictors in the social media setting and effects on information gain online. Computers in Human Behavior, 75, 10081015.

Lepp, A., Barkley, J. E., \& Karpinski, A. C. (2014). The relationship between cell phone use, academic performance, anxiety, and satisfaction with life in college students. Computers in Human Behavior, 31, 343-350.

Levine, L. E., Waite, B. M., \& Bowman, L. L. (2012). Mobile media use, multitasking and distractibility. International Journal of Cyber Behavior, Psychology and Learning (IJCBPL), 2(3), 15-29.

Levine, L. E., Waite, B. M., \& Bowman, L. L. (2013). Use of instant messaging predicts selfreport but not performance measures of inattention, impulsiveness, and distractibility. Cyberpsychology, Behavior, and Social Networking, 16(12), 898-903.

Levy, M. R., and S. Windahl. 1984. Audience activity and gratifications a conceptual clarification and exploration. Communication Research 11(1): 51-78.

Marewski, J. N., Galesic, M., and G. Gigerenzer. 2009. Fast and frugal media choices. Media choice: A theoretical and empirical overview, 107-128.

McQuail, D. 2010. McQuail's mass communication theory. London: Sage.

Meier, A., Reinecke, L., \& Meltzer, C. E. (2016). "Facebocrastination"? Predictors of using Facebook for procrastination and its effects on students' well-being. Computers in Human Behavior, 64, 65-76.

Meyers, M. 1996. News coverage of violence against women: Engendering blame. London: Sage.

Milkman, K. L., Rogers, T., \& Bazerman, M. H. (2008). Harnessing our inner angels and demons: What we have learned about want/should conflicts and how that knowledge can help us reduce short-sighted decision making. Perspectives on Psychological Science, 3(4), 324-338.

Miller, A. (2006). Watching viewers watch TV: Processing live, breaking, and emotional news in a naturalistic setting. Journalism \& Mass Communication Quarterly, 83(3), 11-29.

Myrick, J. G. (2015). Emotion regulation, procrastination, and watching cat videos online: Who watches Internet cats, why, and to what effect? Computers in Human Behavior, 52, 168-176. 
Nabi, R. L., Stitt, C. R., Halford, J., \& Finnerty, K. L. (2006). Emotional and cognitive predictors of the enjoyment of reality-based and fictional television programming: An elaboration of the uses and gratifications perspective. Media Psychology, 8(4), 421447.

Nathanson, A. I., Perse, E. M., \& Ferguson, D. A. (1997). Gender differences in television use: An exploration of the instrumental-expressive dichotomy. Communication Research Reports, 14(2), 176-188.

Oliver, M. B., and A. Bartsch. 2010. Appreciation as audience response: Exploring entertainment gratifications beyond hedonism. Human Communication Research, 36(1), 53-81. doi:10.1111/j.1468-2958.2009.01368.x

Oliver, M. B. (2008). Tender affective states as predictors of entertainment preference. Journal of Communication, 58, 40-61.

Ophir, E., Nass, C., \& Wagner, A. D. (2009). Cognitive control in media multitaskers. Proceedings of the National Academy of Sciences, 106(37), 15583-15587.

Palmgreen, P., Wenner, L. A., \& Rayburn, J. D. (1980). Relations between gratifications sought and obtained: A study of television news. Communication Research, 7(2), 161-192.

Panek, E. T. (2012). Immediate Media: How Instant Gratification, Self-Control, and the Expansion of Media Choice Affect our Everyday Lives.

Panek, E. (2014). Left to their own devices: College students' "guilty pleasure" media use and time management. Communication Research, 41(4), 561-577.

Pengnate, S. F. (2016). Measuring Emotional Arousal in Clickbait: Eye-Tracking Approach, paper presented at the Twenty-second Americas Conference on Information Systems, San Diego, 2016, URL http://aisel.aisnet.org/cgi/viewcontent.cgi?article=1133\&context=amcis 2016

Perse, E. M., \& Ferguson, D. A. (1993). The impact of the newer television technologies on television satisfaction. Journalism Quarterly, 70(4), 843-853.

Petty, R. E., \& Cacioppo, J. T. (1986). The elaboration likelihood model of persuasion. Advances in Experimental Social Psychology, 19, 123-205. doi:10.1016/s0065-2601(08)602142

Prior, M. (2007). Post-broadcast democracy: How media choice increases inequality in political involvement and polarizes elections. Cambridge University Press.

Reed, D. D., Reed, F. D. D., Chok, J., \& Brozyna, G. A. (2011). The" tyranny of choice: Choice overload as a possible instance of effort discounting. The Psychological Record, 61(4), 547.

Reinecke, L., Meier, A., Aufenanger, S., Beutel, M. E., Dreier, M., Quiring, O., \& Müller, K. W. (2016). Permanently online and permanently procrastinating? The mediating role of Internet use for the effects of trait procrastination on psychological health and wellbeing. new media \& society, 1461444816675437.

Reinecke, L., Aufenanger, S., Beutel, M. E., Dreier, M., Quiring, O., Stark, B., \& Müller, K. W. (2017). Digital stress over the life span: the effects of communication load and internet multitasking on perceived stress and psychological health impairments in a German probability sample. Media Psychology, 20(1), 90-115.

Rieskamp, J., Busemeyer, J. R., \& Mellers, B. A. (2006). Extending the bounds of rationality: evidence and theories of preferential choice. Journal of Economic Literature, 44(3), 631-661. 
Rigby, C. S., \& Ryan, R. M. (2016). Motivation for Entertainment Media and Its Eudaimonic Aspects Through the Lens of Self-Determination Theory. The Routledge Handbook of Media Use and Well-Being: International Perspectives on Theory and Research on Positive Media Effects, 34.

Rosenstein, A. W., and A. E. Grant. 1997. Reconceptualizing the role of habit: A new model of television audience. Journal of Broadcasting \& Electronic Media 41(3): 324-344.

Rubinstein, J. S., Meyer, D. E., \& Evans, J. E. (2001). Executive control of cognitive processes in task switching. Journal of Experimental Psychology: Human Perception and Performance, 27(4), 763.

Ryan, R. M., Rigby, C. S., \& Przybylski, A. (2006). The motivational pull of video games: A self-determination theory approach. Motivation and emotion, 30(4), 344-360.

Samuelson, P. A. 1938. A note on the pure theory of consumer's behaviour. Economica 5(17): 61-71.

Schupp, H., Cuthbert, B., Bradley, M., Hillman, C., Hamm, A., \& Lang, P. (2004). Brain processes in emotional perception: Motivated attention. Cognition and Emotion, 18(5), 593-611.

Schwartz, B. 2004. The paradox of choice: Why more is less. New York: Harper Perennial.

Sen, A. K. 1977. Philosophy \& Public Affairs 6(4): 317-344.

Severin, W. J., \& Tankard, J. W. (1997). Communication theories: Origins, methods, and uses in the mass media (4th ed.). New York: Longman.

Shoda, Y., Mischel, W., \& Peake, P. K. (1990). Predicting adolescent cognitive and selfregulatory competencies from preschool delay of gratification: Identifying diagnostic conditions. Developmental Psychology, 26, 978-986. doi:10.1037/00121649.26.6.978

Shoemaker, P. J., Danielian, L. H., \& Brendlinger, N. (1991). Deviant acts, risky business and US interests: The newsworthiness of world events. Journalism \& Mass Communication Quarterly, 68(4), 781-795.

Simon, H. A. 1956. Rational choice and the structure of the environment. Psychological Review 63(2): 129-38.

Simon, H. A. (1983). Alternative Visions of Rationality. In Reason in Human Affairs, ed. H. A. Simon. Stanford: Stanford University Press, 7-35.

Simons, R. F., Detenber, B. H., Cuthbert, B. N., Schwartz, D. D., \& Reiss, J. E. (2003). Attention to television: Alpha power and its relationship to image motion and emotional content. Media Psychology, 5(3), 283-301.

Stanca, L., Gui, M., and M. Gallucci, M. (2013). Attracted but unsatisfied: The effects of sensational content on television consumption choices. Journal of Media Economics 26(2): 82-97.

Stephens, K. K., Mandhana, D. M., Kim, J. J., Li, X., Glowacki, E. M., and I. Cruz. 2017. Reconceptualizing communication overload and building a theoretical foundation. Communication Theory 27: 269-289.

Strack, F., \& Deutsch, R. (2006). Reflective and impulsive determinants of consumer behavior. Journal of Consumer Psychology, 16(3), 205-216.

Strizhakova, Y., \& Krcmar, M. (2003). Do we have access to our viewing motives? Assumptions in and extensions of uses and gratifications. In Annual Conference of the International Communication Association. from http://www. allacademic. com//meta/p_mla_apa_research_citation/1/1/2/2/4/pages11 (Vol. 2244). 
Tandoc Jr, E. C. (2014). Journalism is twerking? How web analytics is changing the process of gatekeeping. New Media \& Society, 16(4), 559-575.

Tangney, J. P., Baumeister, R. F., \& Boone, A. Z. (2004). High self-control predicts good adjustment, less pathology, better grades, and interpersonal success. Journal of Personality, 72, 271-324. doi:10.1111/j.0022-3506.2004.00263.x

Taylor, C. L., \& Friedman, R. S. (2014). Differential influence of sadness and disgust on music preference. Psychology of Popular Media Culture, 3(4), 195-205.

Tewksbury, D., Weaver, A. J., \& Maddex, B. D. (2001). Accidentally informed: Incidental news exposure on the World Wide Web. Journalism \& Mass Communication Quarterly, 78(3), 533-554.

Thaler, R. H., and C. R. Sunstein. 2008. Nudge: Improving decisions about health, wealth, and happiness. New York: Penguin Books

Tversky, A., and D. Kahneman. 1981. The framing of decisions and the psychology of choice. Science 211(4481): 453-458.

Uribe, R., \& Gunter, B. (2007). Are 'sensational' news stories more likely to trigger viewers' emotions than non-sensational news stories? A content analysis of British TV news. European Journal of Communication, 22(2), 207-228.

van der Schuur, W. A., Baumgartner, S. E., Sumter, S. R., \& Valkenburg, P. M. (2015). The consequences of media multitasking for youth: A review. Computers in Human Behavior, 53, 204-215.

Van Koningsbruggen, G. M., Hartmann, T., Eden, A., \& Veling, H. (2017). Spontaneous hedonic reactions to social media cues. Cyberpsychology, Behavior, and Social Networking, 20(5), 334-340.

Weaver A. J., \& Wilson, B. J. (2009). The role of graphic and sanitized violence in the enjoyment of television dramas. Human Communication Research, 35(3), 442-463.

Weaver, A. J. (2011). A meta-analytical review of selective exposure to and the enjoyment of media violence. Journal of Broadcasting \& Electronic Media, 55(2), 232-250.

Weaver, A. J., \& Kobach, M. J. (2012). The relationship between selective exposure and the enjoyment of television violence. Aggressive Behavior, 38(2), 175-184.

Weimann, G., Brosius, H. B., \& Wober, M. (1992). TV diets: Toward a typology of TV viewership. European Journal of Communication, 7(4), 491-515.

Weimann, G. (1996). Cable comes to the Holy Land: The impact of cable TV on Israeli viewers. Journal of broadcasting \& Electronic media, 40(2), 243-257.

Winston, G. C. (1980). Addiction and backsliding: a theory of compulsive consumption. Journal of Economic Behavior \& Organization, 1(4), 295-324.

Wolling, J. (2009). The effect of subjective quality assessments on media selection. Media choice. A theoretical and empirical overview, 84-101.

Xu, S., Wang, Z. J., \& David, P. (2016). Media multitasking and well-being of university students. Computers in Human Behavior, 55, 242-250.

Yeykelis, L., Cummings, J. J., \& Reeves, B. (2014). Multitasking on a computer: Arousal and the frequency, anticipation, and prediction of switching between media content on a computer. Journal of Communication, 64(1), 167-192.

Zillmann, D., \& Bryant, J. (1985). Affect, mood, and emotion as determinants of selective exposure. In D. Zillmann \& J. Bryant (Eds.), Selective exposure to communication (pp. 157-189). Hillsdale, NJ: Erlbaum. 
Zillmann, D. (1988). Mood management through communication choices. American Behavioral Zuckerman, M. (2009). Sensation seeking. In Leary, M. R., Hoyle, R. H. Handbook of individual differences in social behavior. New York/London: The Guildford Press. pp. 455-465.

Zuckerman, M. (2014). Sensation seeking (psychology revivals): Beyond the optimal level of arousal. Psychology Press. 